\title{
Presságios da letra de uma carta de amor
}

\author{
Simone Ravizzini (it) \\ Centro Universitário La Salle, Niterói, RJ, Brasil
}

\begin{abstract}
Resumo
O presente artigo advém da necessidade de explicitar o tema da letra em seu uso na constituição do ser de fala e de sua correlação na instauração do amor. Um amor que se inscreve quando a letra convoca algo do ser para a literalidade, possibilitando, concomitantemente, um lugar para o sujeito bem como para um vazio que o constitui, permanentemente. Desde Freud podemos antever um flerte com a literatura e suas letras. Lacan amplia este percurso para outras artes delineando a imprescindivel função da letra na constituição do sujeito de fala e do advento amoroso. A partir deste legado, almejo perpassar a questão do amor com o vazio que nunca se preenche a partir da inscrição promovida pela letra. Afirma-se neste artigo a importância de sustentar para o amor algo que sempre escapará à função significante, embora demande ser escrito para que possa existir. Desde esta perspectiva se abre um modo de sustentar um lugar para o amor onde a contingência do encontro não se desfaça e os sujeitos possam brincar com o fazer de suas letras.
\end{abstract}

Palavras-chave: amor; gozo; letra; psicanálise; contingência.

\section{Omens of the letter of a love letter}

\begin{abstract}
This article comes from the need to make explicit the theme of the letter in its use in the constitution of the being of speech and its correlation in the establishment of love. A love that is inscribed when the letter summons something from the being to the literality, enabling, simultaneously, a place for the subject as well as for an emptiness that constitutes it, permanently. From Freud we can foresee a flirtation with literature and its letters. Lacan extends this course to other arts by delineating the indispensable function of the letter in the constitution of the subject of speech and the advent of love. From this legacy I aim to go through the question of love with the emptiness that is never filled from the inscription promoted by the letter. It is stated in this article the importance of sustaining for love something that will always escape the significant function, although it must be written in order to exist. From this perspective opens a way of sustaining a place for love where the contingency of encounter does not undo and the subjects can play with the making of their letters.
\end{abstract}

Keywords: love; enjoyment; letter; psychoanalysis; contingency.

[...] Aflição de ser água em meio à terra E ter a face conturbada e móvel. A um só tempo múltipla e imóvel

Não saber se se ausenta ou se te espera. Aflição de te amar, se te comove.

E sendo água, amor, querer ser terra.

(HILST, 2017, p. 90)

\section{Introdução}

A psicanálise, desde Freud, sempre flertou com a literatura. Ele soube extrair dela os significantes que, de uma maneira ou de outra, corroboravam as falas de suas pacientes. Lacan, em seu retorno a Freud, retoma de uma maneira viva não só a teoria, mas alarga a trilha do horizonte de investigação iniciada por Freud. Assim é que em seus seminários e nos Escritos, ele levou a invenção freudiana a um patamar de esquadrinhamento teórico e clínico que possibilitou a interlocução não só com a literatura, mas com o cinema, as artes, a filosofia...

É a partir desse legado lacaniano que penso investigar a questão do amor, sua função de letra no campo da linguagem, seus limites da fala e seus transbordamentos de gozo.

\footnotetext{
^Endereço para correspondência: Consultório Particular. Rua Otávio Carneiro, 100/911 - Icaraí - Niterói, RJ - Brasil. CEP: 24230191. E-mail: simoneravizzini@gmail.com

Os dados completos da autora encontram-se ao final do artigo.
}

\section{Amor ao pé da letra}

No filme de produção franco-britânica $O$ livro de cabeceira (1996), o diretor inglês Peter Greenaway apresenta-nos uma história balizada pela escrita no corpo. É no corpo da filha Nagiko que se escreve a mensagem do pai de felicitação a cada aniversário dela. Um ato que comemora sua existência e que, como o pai sempre enfatiza, também a nomeia. Anos mais tarde, quando a menina se torna mulher, sua vida sexual será marcada por esse ato. Assim, o filme mostra a incessante busca de Nagiko por um "amante ideal", aquele que conseguirá satisfazer a relação de cumplicidade entre corpo, gozo e escrita. Ela se pergunta o que irá preferir: um amante ardoroso, porém desinteressado da caligrafia, ou um amante menos voraz, plenamente articulado ao sabor das letras? Claramente, a personagem principal busca amantes que lembrem o prazer da caligrafia. É pela letra que se instaura para Nagiko a pergunta sobre o amor.

The pillow book (no original) é baseado na história de mesmo nome escrita por Sei Shônagon, uma dama da corte japonesa do século X. Segundo esta escritora, existem duas coisas dignas de confiança na vida: os prazeres do corpo e os prazeres da escrita. Ela afirma ter tido a sorte de experimentar ambos da mesma maneira. Nas palavras dela, descritas no filme, o aroma do papel é como o aroma 
da pele de um novo amante. E o pincel, um instrumento de prazer cujo objetivo nunca é colocado em dúvida, mas cuja eficiência surpreendente sempre se esquece.

Em seu decorrer, o filme nos faz perceber que escrever O livro de cabeceira é poder produzir marcas próprias a cada sujeito. O livro de cabeceira são as escolhas ímpares que Nagiko pôde realizar ao longo de sua vida. Quanto ao amor, ela conclui que este se encontra enquanto se escreve. Ao escrevê-lo, o experimentamos. Há algo de singular na letra que o demarca, que o faz ser de um jeito e não de outro, mas que o faz existir. Uma aposta que se ganha neste filme com tinta e pincel.

Também Lacan (1971/2009) nos propõe a relação da letra com o corpo e o gozo e, posteriormente, com o amor. Ele a delimita quando relata sua viagem ao Japão e descreve a visão de cima do avião sobre a planície siberiana. Neste momento, Lacan se diz influenciado pelo que lhe causou o contato com a língua japonesa e a forma como esta se constitui indissociavelmente da escrita. Ali, entre terra e mar, ele avista o litoral. E, através desse jogo de palavras, aproxima letra, literal do litoral. A letra, tal como o litoral, separa coisas não homogêneas: saber e gozo. Não se trata, absolutamente, de fazer fronteira, pois esta última demarca coisas análogas.

Quanto a mim, eu lhes digo, será que a letra não é o literal a ser fundado no litoral? Porque este é diferente de uma fronteira. Aliás, vocês devem ter observado que essas duas coisas nunca se confundem. O litoral é aquilo que instaura um domínio inteiro como formando uma outra fronteira, se vocês quiserem, mas justamente por eles não terem absolutamente nada em comum. Não é a letra propriamente o litoral? A borda do furo no saber que a psicanálise designa, justamente ao abordá-lo, não é isso que ela designa? (LACAN, 1971/2009, p. 109).

Assim, a letra institui dois campos distintos, estrangeiros um ao outro. Ela comparece como um instrumento oportuno para a inscrição de um discurso, mas não se resume a isso. Se assim fosse, poderíamos pensar a linguagem apenas em seu efeito de sentido, tal como fazem os linguistas. Lacan insiste em dizer que a letra não é equivalente ao significante e que não devemos pensá-la como algo primário a ele, tal como um germe embrionário. Ela designa o furo, mas não almeja escondê-lo posteriormente cobrindo-o com sentido.

De modo que a pergunta que Lacan sublinha com relação à letra é sobre como a linguagem convoca o litoral para o literal. Mais ainda, "como o inconsciente, que ele diz ser efeito de linguagem, comanda essa função da letra" (LACAN, 1971/2009, p. 110). Logo, Lacan preserva a letra em sua relação com algo impossível de dizer ou de compreender, pois a psicanálise demarca que, quando se trata do inconsciente, não há última palavra que venha para explicar o vazio. Quanto a esta, só se poderia pensar nela como "nem palavra, caluda!" (LACAN, 19721973/1985, p. 106).

Portanto, o sentido com que a psicanálise lida comporta sempre esse limite do indizível. Como viemos descrevendo, não há como escamoteá-lo quando se pensa o discurso psicanalítico: um discurso que não rechaça a castração. Por isso a concepção de letra tem nele lugar privilegiado. Ela não se perde se envolvendo na aparência sedutora do sentido, mas ela também não desaparece no puro gozo, permanecendo como "dobradiça" entre dois mundos heterogêneos.

Assim sendo, ao recorrer à pintura japonesa em seu texto Lituraterra, o que Lacan (1971/2003a) aspira a demarcar é o laço desta com a letra e a forma como este laço denuncia a ilusão pictórica. A pintura japonesa, diferente da pintura ocidental até a modernidade, não visa à representação das coisas. Ela institui, por entre as nuvens que apresenta em seus quadros, a função do significante. Do significante como aquele que cobre uma parte da cena, que produz uma ficção. Não obstante, ao mesmo tempo ela denuncia, com o uso da letra caligrafada na lateral de seus quadros, que aquilo é mesmo um quadro, um semblante de imagem. Essas letras caligrafadas constituem, assim, a rasura do significante. Elas distinguem-se por serem ruptura do que constituía forma, mostrando como a ficção promovida pelo significante opera.

Para Lacan (1971/2009), isso fica muito evidente ao usarmos o exemplo da planície, pois na planície antevemos um traço que desponta. Este traço é reflexo de um escoamento. Neste escoamento podemos perceber o que ocorre em dois momentos: o que se marca pelo traço e aquilo que ele apaga. De forma que o literal rasga o que havia de homogêneo no gozo. Ali, a letra borda o furo no limite do saber, mas ao mesmo tempo ela o realiza.

A partir desse movimento, Lacan (1971/2009) elabora uma correlação para o sujeito e a questão da letra, pois é pelo apagamento do traço que o sujeito pode ser designado. O sujeito se institui parte na letra e outra parte nisso que ela destitui.

Litura, lituraterra. Rasura de traço algum que seja anterior, é isso que do litoral faz terra. Litura pura é o literal. Produzir essa rasura é reproduzir a metade com que o sujeito subsiste... Produzir a rasura sozinha, definitiva, é essa a façanha da caligrafia (LACAN, 1971/2009, p. 113).

É conveniente demarcar que na caligrafia japonesa não se trata de um traço qualquer, mas de um traço do sujeito. Um japonês pode levar a vida inteira praticando até chegar ao traço vertical ideal. Lacan enfatiza que na escrita japonesa há algo ímpar no gesto da mão, algo que abate o universal. O importante é que a esse gesto da escrita adiciona-se outra dimensão, "uma diz-mansão do sujeito" (LACAN, 1971/2009, p. 112) Portanto, é um saber fazer com a letra que constitui um lugar para o sujeito. Essa é a clareza destacada pela língua japonesa, visto que permanece associada à escrita.

O psicanalista Antoni Vicens (2008) declara que o interesse de Lacan pelos autores orientais já comparece desde o seminário A Lógica da fantasia (1966-1967). Ali ele se refere a Shitao, um dos nomes adotados pelo primeiro calígrafo chinês do século XVII. Lacan haveria recomendado a seus ouvintes que buscassem o trabalho de Shitao, pois este seria o melhor modo de pensar o tema do traço unário e a questão da escrita como anterior à própria fala. 
O significado do nome Shitao é próximo a "onda de pedra". Seu nome é assim escolhido por sustentar a conjunção de campos diferenciados: o que é mais rígido com o que é mais fluido: da pedra com a água. Vemos com isso a demarcação de coisas heterogêneas que nunca se misturam. Vicens (2008) aproveita este ensejo para correlacionar a entrada do simbólico no advento da pulsão apresentada por Freud (1915/1974) em Os instintos e suas vicissitudes. Segundo Vicens, pode-se conjugar Freud, Lacan e Shitao. Assim, ele se apropria de um exemplo freudiano que associa o movimento da lava e o fluxo pulsional visando demarcar o mesmo movimento que nos aponta Lacan quando fala da função da letra ao convocar o litoral ao literal. Segue a passagem freudiana:

Podemos dividir a vida de cada instinto numa série de ondas sucessivas e isoladas, cada uma delas homogênea durante o período de tempo que possa vir a durar, qualquer que seja ele, e cuja relação de umas com as outras é comparável às sucessivas erupções de lava. Podemos então figurar a primeira erupção mais original do instinto como se processando de forma inalterada sem experimentar qualquer desenvolvimento. A onda seguinte seria modificada desde o início - sendo transformada, por exemplo, de ativa em passiva - e seria então, com essa nova característica, acrescentada à onda anterior, e assim por diante. Se fossemos então proceder a um levantamento do impulso instintual desde seu começo até um determinado ponto, a sucessão de ondas que descrevemos inevitavelmente apresentaria o quadro de um desenvolvimento definido do instinto (FREUD, 1915/1974, p. 152).

A lava pode ser entendida como uma onda de pedra. A solidificação de suas ondas cria o efeito de uma história na qual se coagula algo que foi, inicialmente, fluido e maleável. A petrificação de uma primeira onda constitui o caminho pelo qual deverá passar uma nova onda. Uma vez delineado este caminho, a pulsão, tal como a lava, procurará repeti-lo em busca de sua satisfação. É pelo simbólico que podemos dar certa ordem ao movimento pulsional. Assim, contingencialmente, a partir deste primeiro trilhamento, engendra-se uma repetição que dá direção à pulsão. De acordo com Vicens (2008), essa metáfora de Freud parece seguir o pensamento do calígrafo chinês; isso porque, se a tinta provém da pedra, ela recupera sua condição lapidária, uma vez que, para escrever o traço adequado, a mão do calígrafo precisou seguir os movimentos de seu corpo. É preciso incluir a contingência no traço que promove a escritura.

Certamente, na arte a primeira coisa que se precisa aprender é o primeiro traço, quer dizer, aprender é fundamentá-lo na contingência para qual o corpo dá seu apoio. Os demais seguirão esse traço. A prova disso é que quando um crítico de arte estuda a pintura chinesa, ele não parte de uma primeira visão do conjunto, mas da forma singular do traço. Esse traço é o mais pessoal e original: é impossível ser copiado, pois no próprio traço condensa-se toda a arte de escrever ou pintar. O traço vem do corpo, de sua singularidade, guarda a forma não repetível do gesto de cada um. O traço guarda tudo que é importante no próprio movimento da criação. É a partir dessa singularidade imprevisível que se abre então o espaço da significação (VICENS, 2008, p. 147).
Então, antes deste traço que nos marca, nada existe. Enquanto seres de fala, precisamos passar pelo $\mathrm{Ou}-$ tro, Outro da Linguagem, para termos existência. Se há uma natureza que nos constitui, ela pode ser chamada de Linguagem. Assim, o ser falante não preexiste ao encadeamento significante que se inicia com o traço único. Todavia, precisamos também demarcar que tal traço cinge o vazio que subsiste em nós. Ele comparece entre os demais traços subsequentes que buscamos para nos representar, sempre separados em sua diferença. Por conseguinte, sob este prisma, mesmo o vazio não se apresenta a priori, mas se constitui a partir do que se cria. Ele se inscreve entre o primeiro traço e todos os outros.

Traduzido em termos de estrutura, é o vazio que se instala de maneira irreparável entre S1 e S2. Mais ainda, é precisamente esse vazio que faz passar o rasgo ou traço unário ao segundo traço com o qual o traço primeiro deixa de sê-lo para passar a ser um significante. Dito de outro modo, o S2 é o Outro, o que se precipita a preencher o vazio que cria o aparecimento do S1. Mas o S2 nunca poderá preenchê-lo, sempre ficará um resto, é isso que faz o S2 uma série que deve continuar (VICENS, 2008, p. 148).

Sob esse mesmo prisma, Lacan (1972-1973/1985) vai falar da carta de amor. A carta/lettre como escrito. Isso porque a letra é lida tal como fazemos com uma carta. Ela chega sempre ao seu destino, ou seja, confere um lugar àquele que a detém. A letra demarca uma posição para os que habitam a linguagem. Sabemos que é pelo jogo de letras que se instauram os discursos; não esqueçamos ser também pelo objeto $a$ que podemos pensar aquilo que ocorre com a escolha amorosa. Por conseguinte, é ainda com a letra da carta que Lacan (1972-1973/1985, p. 113) vai afirmar podermos "fazer algo de sério" no amor, isso porque cabe à letra dar início à série significante que pode se constituir com a poesia do amor.

A questão da carta para Lacan (1956/1998) já é evidenciada em seu texto de abertura dos Escritos: $O$ seminário sobre " $A$ carta roubada", embora neste momento ainda não se articule ao gozo. Isso ocorrerá posteriormente no seminário De um discurso que não fosse semblante (LACAN, 1971/2009) Neste texto sobre a carta, Lacan se ampara no conto de Edgar Allan Poe, escrito em 1844. Ele se configura como o último caso do detetive Dupin, de uma série de novelas realizadas por Poe.

Assim, o conto se passa no período de 1800 . O detetive Dupin, personagem principal, é morador de Paris e amigo do narrador da história. Tal narrador nos relata que em certo dia o chefe de polícia parisiense procura Dupin almejando que este o ajude a solucionar o roubo de uma carta. A carta havia sido furtada por um proeminente Ministro dos aposentos da rainha. Embora o chefe de policia já houvesse realizado várias buscas pela carta na casa do Ministro, ele ainda não a havia encontrado. Diante de tal prerrogativa, Dupin lhe diz que não teria mais nada a lhe aconselhar. 
Passado um mês do encontro entre Dupin e o delegado, este volta a procurá-lo, pois não havia ainda conseguido recuperar a carta. Ele o procura ainda para receber conselhos, mas Dupin o surpreende entregando-lhe finalmente a própria carta roubada.

Para que possamos saber como esse desfecho ocorreu, no conto, a personagem que figurava como narrador desta história pergunta a Dupin como ele havia realizado tal feito. Assim, Dupin relata sua busca. Como o chefe de polícia havia subestimado o Ministro por ser este um poeta e levara em conta todo o seu tempo de investigador na polícia, durante o qual teve sempre que lidar com casos cujos objetos escondidos por criminosos foram ocultados de forma rebuscada, ele não considerou que o Ministro, também matemático, agiria com simplicidade neste caso. Portanto, levando em conta tal perspectiva, Dupin ao visitar o Ministro, enquanto conversavam, observou um porta-cartas pendurado no meio da lareira com um documento que reconhecera ser a carta procurada: tão à mostra e tão invisível. Ele a reconhecera pelo selo, pois seu aspecto estava disfarçado em seu reverso.

Tendo isto em vista, quando deixa o apartamento o detetive esquece propositalmente sua tabaqueira, para ter a desculpa de poder retornar num outro dia. Havia planejado de antemão, durante o momento em que estivesse no apartamento do Ministro, a simulação de um tiroteio na rua que o distrairia, levando-o à janela e distante da carta. De tal forma, Dupin trocou a carta por uma cópia, deixando um recado nesta última para o Ministro, remetendo-o a uma vingança por uma peça pregada por este último outrora ao próprio Dupin. Ali ele dizia: "um desígnio tão funesto, se não é digno de Atreu, é digno de Tieste" (POE, 1844/1981, p. 186). Quanto à carta, não poderia ser deixada em branco. Assim, Dupin lega ao Ministro sua letra em lugar da carta furtada.

O que a Lacan interessa neste conto é a ideia de que o que está escondido é precisamente o que vai faltar em seu lugar. E só se consegue dizer disso porque algo poderá vir a substituí-lo: a letra. Quanto a isso, poeticamente, Lacan enfatiza que "Os escritos carregam ao vento as promissórias em branco de uma cavalgada louca. E se eles não fossem folhas volantes, não haveria letras roubadas, cartas que voaram" (LACAN, 1956/1998, p. 30).

Assim sendo, é por poder realizar um desvio que a carta possui um trajeto que lhe é próprio. É ela que confere moradia ao sujeito ao se submeter à linguagem. Podermos perceber nesta singularidade atribuída à carta o que proporciona valor a este conto sob o olhar psicanalítico. Sua função desviante mostra como o significante se sustenta em um deslocamento, designando lugares para os sujeitos por ela demarcados.

Mas quanto à cartalletra, quer a tomemos no sentido de elemento tipográfico, de epístola ou daquilo que faz o letrado, diremos que o que se diz deve ser entendido à letra, que há uma carta a espera de vocês com o carteiro, ou que vocês têm cartaslletras - mas nunca que haja la lettre em alguma parte, não importando a que título ela lhes diga respeito, nem que seja para designar a correspondência em atraso. [...]
Pois o significante é unidade por ser único, não sendo, por natureza, senão símbolo de uma ausência. E é por isso que não podemos dizer da carta/letra roubada que, à semelhança de outros objetos, ela deva estar ou não estar em algum lugar, mas sim, diferentemente deles, ela estará e não estará onde estiver, onde quer que vá (LACAN, 1956/1998, p. 27).

De tal modo, as questões que a carta apresenta circunscrevem um problema mais amplo. Ela comparece quando o outro amado está ausente, remontando a um aspecto imprescindível da letra: o de servir "supostamente" como intermediário na relação com o outro, almejando garantir uma pretensa proximidade entre aquele que ama e aquele que é amado, quando na realidade é concorrente do corpo que não está presente. A letra, na medida em que visa ao enlace com o Outro, sela sua separação. Sendo assim, a função da carta resta paradoxal: para que a carta trace seu destino, para que chegue ao amado, é preciso estar distante dele.

A carta de amor é mesmo um exemplo curioso. $\mathrm{O}$ autor da carta pode não ser verdadeiramente o amante. As cartas podem ser falsas. Nada disso importa. Sem dúvida, ela também não é homogênea, já que pode apresentar-se sob uma variedade de formas. Ela pode ser elaborada sobre tipos de papéis diferentes, pode ser colorida ou em preto e branco, comportar marcas de batom para representar o envio de um beijo, perfumada ou não, em forma de poema ou mesmo uma poesia citada para ressaltar o amor pretendido.

Quando antevemos esta característica múltipla das cartas de amor, precisamos nos interrogar acerca do que haveria em comum entre todas elas. A resposta consiste precisamente no uso da letra. A carta demanda ser sempre bem escrita. De forma que, mesmo não correspondendo ao amor apresentado pela carta, suas letras bem arranjadas promovem um efeito de prazer em quem as recebe. Perante este aspecto da carta de amor, Soler (2011, p. 13) relata:

Assim, as letras de amor vão desde os significados do Outro, desde a fala mais clichê, até a invenção verbal lá onde o Outro silencia. Embora díspares todos falam de forma semelhante. É como se o amor tivesse que ser barulhento, necessitando ser dito, não apenas para ser notado, mas simplesmente para ser. Isto é tão verdadeiro que seria difícil imaginar um amante que escrevesse uma só carta de amor. É preciso que a carta seja bem escrita. Este dizer belo, que não é o bem dizer, revela sem dúvida seu estatuto de objeto, pelo menos estético.

Cyrano de Bergerac, obra-prima de Edmond Rostand (1897/2002), sucesso na França no final do século XIX, acentua o poder da bela escrita no transcorrer de seu texto. $\mathrm{O}$ autor transforma seu personagem principal em um herói romântico, capaz de morrer por sua amada sem mesmo revelar a autoria das cartas que surpreendem a bela Roxana. Quanto às cartas, o talentoso personagem não as retém. Retê-las, como nos diz Lacan (1971/2009), seria destituí-las de sua função. De modo que Bergerac escreve para que outro conquiste sua amada em seu lugar. É pela leitura das cartas que Roxana se encanta. Sobre a feitura das cartas, Cyrano escreve: 
Pois, escrevamos, sim.

Essa carta de amor que eu faço a vida inteira,

E que refaço em mim cem vezes, de maneira

Que, se puser minha alma ao lado do papel,

Basta-me só tirar-lhe a cópia bem fiel.

(ROSTAND, 1897/2002, p. 102).

Assim, Bergerac ilustra sublimemente a impossibilidade da relação sexual e o papel da letra perante isso. A impossibilidade da relação sexual é uma formulação lógica através da qual Lacan pôde escrever a ausência da relação entre os sexos. Não se trata de afirmar que o sexo como ato não exista, mas de sublinhar que há uma fatalidade entre eles no que diz respeito à possibilidade de plena fusão. Por isso, são necessárias diferentes construções entre um e outro para que se possa responder a essa ausência irremediável. Neste caso, Cyrano não coloca seu corpo em jogo porque entende que seu grande nariz irá atrapalhá-lo na conquista de sua amada. A seu ver, tal enormidade de seu nariz faria com que Roxana fixasse ali seu olhar, não havendo espaço para nada além. Ele imagina ocorrer uma simetria entre Christian, Roxana e ele próprio. Entretanto, por não existir tal simetria no que diz respeito à relação sexual, por um ser de fala nunca complementar o outro, como nos sublinha Lacan, Roxana continua a demandar palavras. Isso porque, a letra que poderia representar o que seria uma mulher, sempre escapole nas entrelinhas.

Graciela Brodsky (2008) ampara-se também neste exemplo, descrevendo que, quanto a Bergerac, há um equívoco corriqueiro de um homem no que é inerente a uma mulher. Ele supõe poder determinar o que ela quer, não sabendo da inexistência da relação sexual:

Mas como não há simetria, o que Roxana quer são palavras. Cyrano escreve, Christian fala e Roxana se enamora. Quando Christian não tem mais os versos escritos por Cyrano, Roxana lhe diz: "fale para mim", e ele diz: te amo!. Roxana lhe diz: "já sei, mas fala para mim". Christian lhe diz: "te amo muito", e Cyrano finalmente lhe diz: "Brodez, brodez!" - enfeita, aumenta, acrescenta mais coisas! Finalmente Roxana se vai sem se interessar por qualquer coisa. Nessa cena vê-se perfeitamente três lugares: daquele que fala e não coloca o corpo; daquele que quer a nuca mas não sabe como obtê-la; daquele que espera as palavras que não vêm. É preciso o desenlace final para que os amantes se encontrem quando a relação sexual já é impossível, visto que Roxana está no convento e Cyrano está moribundo (BRODSKY, 2008, p. 190).

Portanto, tal como no Livro de Cabeceira, em Cyrano de Bergerac mais importante do que a retribuição do amor é que este possa ser escrito. Escrito como algo que marca o sujeito e que cifra seu gozo. Um fazer com a letra que se realiza durante toda sua vida na medida em que é preciso o advento do significante para que se organize o gozo. Esta carta, Cyrano vai escrevê-la como o que ele pensa ser decalque de sua alma.

Lacan (1972-1973/1985) não iria refutá-lo, e lhe diria que só é mesmo possível amar e ter uma alma quando nos servimos da escrita. É como uma produção que ela pode comparecer. Assim, "O amor alma a alma" (LA-
CAN, 1972-1973/1985, p. 113). Ela se produz como uma ficção que se forja a partir da letra que também constitui a poesia do amor. Tal formulação lacaniana só pode ser pensada porque o amor não comparece configurado por uma essência a priori ao significante. Sua tessitura é apenas doce ilusão: uma concha que permanecerá vazia.

Quanto ao fazer do amor, o que vemos é que ele insiste em constituir laço onde isso não é possível. Neste advento, ele visa unir aquilo que não cola jamais, porque ao amor é dada a possibilidade de fazer signo. Uma vicissitude interessante relativa ao signo, tal como nos adverte Lacan, é precisamente sua possibilidade de enlace na "disjunção de duas substâncias que não teriam nenhuma parte em comum" (LACAN, 1972-1973/1985, p. 28) Por conseguinte, o empreendimento amoroso persiste na eterna tentativa de unir coisas disjuntas. Seu problema reside em esquecer que de dois não se pode fazer Um. Assim, discordamos de Aristófanes quando este insiste, em $O$ Banquete de Platão (1996), que seríamos seres em busca de nossas metades perdidas cujo encontro resultará em perfeito encaixe. Não somos seres partidos que iremos nos completar quando encontrarmos nossa "parte perdida". Na verdade, o amor terá sempre que lidar com isso que não se completa, na medida em que o objeto falta. O amor é uma resposta persistente ao confronto com a castração e com o não haver da relação sexual. De forma que a carta de amor tem o dom de funcionar onde o objeto não consegue corresponder: onde resta inadequação.

Por isso Lacan designa a posição amorosa como aquela que demanda sempre mais amor perante a impossibilidade de resposta plena a esta demanda. Caberia ao amor essa função. Assim, retomemos em nosso percurso a ideia de que "o amor demanda o amor. Ele não deixa de demandá-lo. Ele o demanda... mais... ainda. Mais, ainda, é o nome próprio desta falha de onde, no Outro, parte a demanda do amor" (LACAN, 1972-1973/1985, p. 13). Sabemos que esta falha será sempre respondida de forma insuficiente pelo amor em sua costura. Costura que se escreve pela letra.

A proximidade com o uso da letra permite a Lacan (1972-1973/1985) ver então a poesia, contida em uma carta de amor, como o menos bobo dos dizeres. Isso porque só a poesia é capaz de inventar aquilo que o Outro não saberia escrever, aquilo que resta vazio. Ela possibilita inventá-lo belamente, fazendo letra onde a palavra é muda.

O poeta Fernando Pessoa (1969) também compactua com Lacan ao escrever que as cartas de amor precisam, necessariamente, ser ridículas. Elas empreendem o impossível de realizar, muitas vezes inventando um linguajar que é próprio apenas aos amantes e que soa estranho a quem delas não participa.

Todas cartas de amor são ridiculas.

Não seriam cartas de amor se não fossem ridículas.

Também escrevi em meu tempo cartas de amor

Como as outras,

Ridiculas.

As cartas de amor, se há amor, têm de ser ridiculas.

Mas, afinal, só as criaturas que nunca escreveram

Cartas de amor

É que são ridículas

(PESSOA, 1969, p. 399).

Fractal, Rev. Psicol., v. 32 - n. 3, p. 298-305, 2020 
Poderíamos pensar que a carta, como suporte da letra amorosa, em papel, estaria em vias de extinção. Novos são os meios virtuais que utilizamos hoje no lugar da carta em papel. Temos e-mails, WhatsApp, Facebook e o que mais vier por aí, depois do advento da internet e do telefone celular. Ainda assim, a estrutura da carta permanece, embora submetida a meios diferenciados. Qual seria então esta estrutura?

Segundo Soler (2011, p. 14), as cartas de amor sempre dizem respeito à tentativa de preenchimento do vazio que apresenta para o sujeito em seu "encontro" com o objeto.

E, no fundo, do que fala a carta de amor? Das maravilhas do objeto agalmático que preencheriam a falta e a solidão, falam como se estivessem ali, mas escrevem sobre um fundo de ausência, ausência conjuntural para os amantes separados, porém, mais essencialmente, são cartas dirigidas a um amor impossível. Que se pense nas cartas de Macedônio Fernandez à Elena Bellemort, desaparecida, ou nas cartas ao amor traído da religiosa portuguesa. Por isso, são cartas que não apenas admiram, se deslumbram, exaltam o objeto, mas que gritam através do escrito, que denunciam, que se lamentam, choram, comemoram ou procuram ressuscitar. Em todos os casos, elas falam de mim, da minha dor, da minha falta, da minha raiva, do meu desespero e da volúpia de sofrer por amor.

A artista plástica francesa Sophie Calle, um dos relevantes nomes da arte contemporânea, vai nos oferecer a ilustração para esta questão em uma de suas exposições. A partir do e-mail de rompimento recebido de um antigo namorado em 2004, o escritor Gregoire Bouillier, que lhe dizia como derradeira frase Prenez soin de vous, ou seja, "Cuide de você", Calle procura inventar um peculiar enlace com o outro.

Ela encaminha este último conselho de seu amante a mais de 107 intérpretes, escolhidos em diferentes profissões, em sua maioria mulheres. Algumas das colaboradoras são famosas, como a atriz Jeanne Moreau e a compositora Laurie Anderson, outras são anônimas. Calle incluiu também duas bonecas e um papagaio fêmea, na tentativa de responder ao derradeiro contato. Quanto a este, não lhe vinham palavras. Diante do impossível de lidar, do impossível de dizer, vai procurar a palavra apropriada literalmente no Outro.

Então, reunindo fotografias, vídeos, textos e outras formas de interpretação, ela produziu uma exposição, que percorreu o mundo a partir de sua estreia na $52^{\mathrm{a}} \mathrm{Bie}-$ nal Internacional de Arte de Veneza, em 2007. Em 2010, Cuide de Você foi realizada no Rio de Janeiro, ocupando o Museu de Arte Moderna (MAM). “Analisá-la, comentá-la, interpretá-la, dançá-la, cantá-la. Dissecá-la, esgotá-la. Fazer-me compreender. Falar no meu lugar. Uma maneira de sentir o tempo do rompimento. No meu ritmo. Cuidar bem de mim", afirma Sophie Calle no texto de apresentação do evento.

Sua exposição faz derivar respostas oriundas da falta, abarcando escritos de outras mulheres. Escritos tomados para si e organizados de forma ímpar em seu trabalho. Cuidar de si é então produzir algo inédito perante o vazio se utilizando de diferentes suportes, embora todos amparados pela letra. Com esta visada, Calle não almeja conselho ou conciliação, mas escrever algo que possa ser lido por outras pessoas: cartas abertas que possam ser apropriadas por quem assim desejar. Cartas de amor, na medida em que falam de sua dor, elaboradas sob uma configuração mais contemporânea. Assim, a carta pode ser folha de papel, mas também qualquer suporte sobre o qual seja possível escrever palavras de amor.

Mas tomemos pela mão aquilo que a palavra de amor não consegue escrever. A inexistência da relação sexual e a impossibilidade de um significante que determine $A$ Mulher como universal condicionam os impasses da função do gozo sexual. Como foi pontuado, Lacan (19721973/1985) procura escrever a sexuação em termos de uma escrita lógica. Logo, não se trata de uma distinção anatômica entre os sexos, mas de instituir modalidades de gozo que se estruturam em torno da castração pela ação da linguagem. De tal forma, quando nos referimos, em psicanálise, ao masculino e ao feminino, estamos falando de posições sexuadas, e não do sexo anatômico ou mesmo dos gêneros enquanto tais. Dessa maneira, existem particularidades no modo como homens e mulheres podem se inserir na sexuação e na sua relação com o falo, enquanto o que produz representação. Por ser o falo um significante privilegiado por Lacan, ele é o que cobre e ao mesmo tempo faz obstáculo à relação suposta com o outro. Ele também é o que possibilita algum saber sobre o gozo, mas não-todo.

Diante disso, Lacan (1972-1973/1985) elabora duas modalidades de gozo. Localiza o homem como aquele que está submetido totalmente à função fálica, afeito à administração dos sentidos estabelecidos, dos semblantes, e a mulher como aquela que está não-toda submetida à função fálica, o que lhe permite experimentar um gozo a mais, suplementar, efeito do encontro do gozo fálico e do gozo além do falo.

Não há mulher senão excluída pela natureza das coisas que é a natureza das palavras [...] Nem por isso deixa de acontecer que, se ela está excluída pela natureza das coisas, é justamente pelo fato de que, por ser não-toda, ela tem, em relação ao que designa de gozo a função fálica, um gozo suplementar (LACAN, 1972-1973/1985, p. 99).

Notem que Lacan diz "suplementar" e não complementar, procurando evitar a ideia de totalidade. Portanto, a mulher como complementar ao homem não existe, na medida em que não encontramos um sujeito mulher em simetria ao sujeito fálico. A mulher é, desde sempre na relação com o falo, a que não tem. Ela se constitui uma a uma, perante o "nada" que não se pode escrever. O feminino comporta, assim, uma "inconsistência", um gozo ilegível que resta no corpo, para além da borda traçada pela letra.

Em "Mulheres e semblantes", Miller (2011, p. 50) salienta: "por que não dizer que as mulheres parecem, às vezes e na medida do possível, mais amigas do real? De qualquer forma, isso se explica pelo fato de elas não terem necessariamente a mesma relação com a castração que os homens". Tal elo pode ser evidenciado na experiência clínica por um discurso que aponta para a falta de 
identidade e de consistência, para o estranho sentimento de fragmentação corporal, para a curiosa ligação com o infinito e para o sentimento de incompletude radical, efeitos da relação inevitável que as mulheres travam com a escrita que falha. Podemos dizer que o feminino abarca este "para além" do litoral da letra, abrindo as portas para outra escrita mais inventiva.

Deste modo, a letra não apenas ocupa o lugar de ficção na escrita, mas também propicia tanger o que resta sem medida, ao infinito, inerente à lógica do não-todo. No alinhavar de nosso percurso, a carta de amor pode ser em si o litoral entre o sujeito que fala e o gozo que habita seu corpo, levando em conta que nem tudo pode ser lido.

Nesta construção de saber, Lacan (1972-1973/1985) situa a letra como algo da ordem de um divertimento. Um brincar que aponta para outra satisfação advinda com a linguagem, muitas vezes esquecida por estarmos sempre privilegiando o que é relativo ao sentido. Se, de um lado, a linguagem possibilita a comunicação, de outro, reside uma satisfação na própria fala. "Está aí o começo da letra, da carta, um divertimento de alma, um divertimento" (LACAN, 1972-1973/1985, p. 115). Quem não se lembra do vídeo que circulou na internet no qual irmãos gêmeos conversavam entre si por longos minutos? Um dizia: "lá, lá, lá, lá, lá, lá", e o outro respondia, aos sorrisos, “lá, lá, lá, lá, lá, lá...”, em uma conversa quase infinita e extremamente divertida para ambos. Certamente, não se tratava ali de qualquer compreensão, mas de gozar com a fala. Ficaram assim por quase vinte minutos, se "entendendo" sem nenhum dito. Para nós, "o dizer fica esquecido por trás do dito" (LACAN, 1973/2003b, p. 449), ou seja, nos esquecemos de suas letras e de seu fazer. Assim, o dizer só pode ser demonstrado ao escapar do dito. E não é isto precisamente que faz um analista quando pode se furtar a compreender a fala de um analisando e ler as letras de seu dizer?

Sob esta perspectiva, quando o falo realiza o empreendimento que engendra o sentido, ele permite inventar através de suas diversas artimanhas, o que será utilizado para operar diante da inexistência da relação sexual. Para isso, ele oferece algo que sustenta os discursos.

Pela função que lhe advém do discurso, ele passou ao significante. Um significante pode servir para muitas coisas, tal como um órgão, mas não para as mesmas. [...] Quanto à função de isca, se é o órgão que se oferece ao anzol às voracidades que situamos a pouco - digamos originárias (d'orygine) - o significante, ao contrário, é o peixe que engole aquilo que os discursos precisam para se sustentar (LACAN, 1973/2003b, p. 456).

Portanto, de acordo com o que vimos até aqui, e tal como nos ensina Lacan, só o amor permite ao gozo condescender ao desejo. Mas não só. Nesta imersão sobre a letra de uma carta de amor, o desejo e o gozo, sempre haverá uma cota não simbolizável. Então, o que nos resta é escrever, tal como Cyrano, Pessoa, Sophie Calle? Escreviver para fazer ficção com a vida? São questões que cernem e concernem à existência dos seres de fala.

\section{Informações sobre a autora:}

\section{Simone Ravizzini}

(iD) https://orcid.org/0000-0001-8130-8661

\section{(9) http://lattes.cnpq.br/8233551200025079}

Doutora em Teoria Psicanalítica pela Universidade Federal do Rio de Janeiro com a tese "A Concha Vazia do Amor: amor, contingência e semblante”. (2016) Mestre, também pela Universidade Federal do Rio de Janeiro, com a dissertação "O que não podem dizer as palavras: o limite da Interpretação". (2000) Possui especialização em A Psicanálise e a Clínica, pela Universidade Federal Fluminense (1996). Graduada em Psicologia pela Universidade Federal Fluminense (1995). Graduada em Comunicação Social - Publicidade, pela Pontifícia Universidade Católica - PUC-RJ (1988). Coordenadora e professora do curso de Pós-graduação A Clínica Psicanalítica na Contemporaneidade da Unilasalle, Niterói,RJ. (2019-dias atuais) Professora no curso de Psicologia da Universidade Estácio de Sá (2000-2017), em Niterói, RJ, onde lecionou matérias como Teorias e Sistemas II, Clínica Psicanalítica, Estágio Básico em Clínica I, dentre outras matérias com foco em Psicanálise e Clínica. Além disso, possui experiência como supervisora no Serviço de Psicologia Aplicada da mesma Universidade (2015 -2017). Orientação de grupos de estudos, sob o título Uma Leitura do Seminário 1, introdução à teoria e à clínica em Lacan, no consultório particular em Niterói. (2018) Psicanalista, atende adultos e adolescentes continuamente no consultório desde 1997 e supervisiona outros psicanalistas em seus casos clínicos (2015-2018).

\section{Como citar este artigo:}

\section{ABNT}

RAVIZZINI, Simone. Presságios da letra de uma carta de amor. Fractal: Revista de Psicologia, Niterói, v. 32, n. 3., p. 298-305, set./out. 2020. https://doi.org/10.22409/1984-0292/v32i3/5935

\section{APA}

Ravizzini, S. (2020, Setembro/Outubro). Presságios da letra de uma carta de amor. Fractal: Revista de Psicologia, 32(3), 298-305. doi: https://doi.org/10.22409/1984-0292/v32i3/5935

\section{Copyright:}

Copyright (C) 2020 Ravizzini, S. Este é um artigo em acesso aberto distribuído nos termos da Licença Creative Commons Atribuição que permite o uso irrestrito, a distribuição e reprodução em qualquer meio desde que o artigo original seja devidamente citado.

Copyright (C) 2020 Ravizzini, S. This is an Open Access article distributed under the terms of the Creative Commons Attribution License, which permits unrestricted use, distribution, and reproduction in any medium, provided the original article is properly cited.

\section{Referências}

BRODSKY, Graciela. O homem, a mulher e a lógica. Latusa: Revista da Escola Brasilera de Psicanálise, Rio de Janeiro, n. 13, p. 171-192, 2008.

FREUD, Sigmund. Os instintos e suas vicissitudes (1915). In: SALOMÃO, Jayme (Org.). Obras Psicológicas Completas de Sigmund Freud. Rio de Janeiro: Imago, 1974. v. 14, p. 129-162. Edição Standard Brasileira.

HILST, Hilda. Da poesia. São Paulo: Companhia das Letras, 2017.

LACAN, Jacques. O Seminário: mais, ainda (1972-1973). Rio de Janeiro: J. Zahar, 1985. livro 20. 
LACAN, Jacques. Seminário sobre "a carta roubada" (1956). In:___ Escritos. Rio de Janeiro: J. Zahar, 1998. p. 13-68.

LACAN, Jacques. Lituraterra (1971). In: Outros escritos. Rio de Janeiro: J. Zahar, 2003a. p. 15-28.

LACAN, Jacques. O aturdito (1973). In: Outros escritos. Rio de Janeiro: J. Zahar, 2003b. p. 448-497.

LACAN, Jacques. O Seminário: de um discurso que não fosse semblante (1971). Rio de Janeiro: J. Zahar, 2009. livro 18.

MILLER, Jacques-Alain. Mulheres e semblantes. In: CALDAS, Heloisa; MURTA, Alberto; MURTA, Claudia. (Org.). O feminino que acontece no corpo: a prática da psicanálise nos confins do simbólico. Belo Horizonte: Scriptum, EBP, 2011. p. 49-89.

O LIVRO de cabeceira (The Pillow Book). Direção: Peter Greenaway. Produção: Kees Kasander. Roteiro de Peter Greenaway, adaptado da obra Makura no Sôchi, de Sei Shônagon. Reino Unido: Centurion, 1996. 1 DVD (126 min), son., color.

PESSOA, Fernando. Obra poética. Rio de Janeiro: José Aguilar, 1969.

PLATÃO. Diálogos I: Mênon, Banquete, Fedro. Rio de Janeiro: Ediouro, 1996.

POE, Edgar Allan. A carta furtada (1844). In: . Ficção

completa, poesia \& ensaios. Rio de Janeiro: Nova Aguilar, 1981. p. 171-198.

ROSTAND, Edmond. Cyrano de Bergerac (1897). São Paulo: Nova Cultural, 2002.

SOLER, Colette. As cartas de amor. In: ABRAMOVITCH, Sheila; BORGES, Sonia (Org.). O amor e suas letras. Rio de Janeiro: 7Letras, 2011. p. 11-20.

VICENS. Antoni. Traço e repetição em O avesso da psicanálise. Latusa: Revista da Escola Brasilera de Psicanálise, Rio de Janeiro, n. 13, p. 137-152, 2008. 